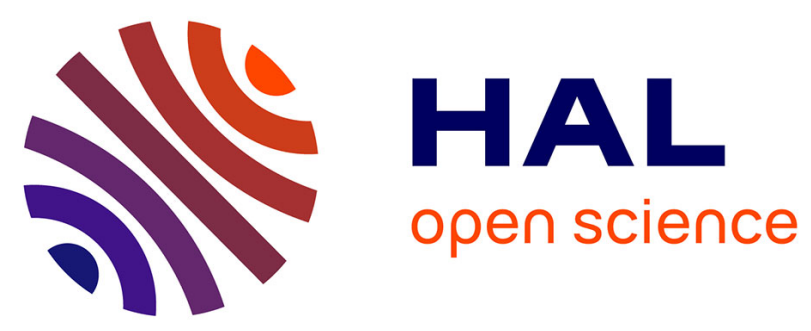

\title{
Postoperative Spinal Implant Infections in Children
}

Aurore Lamberet, Philippe Violas, Sylvie Buffet-Bataillon, Antoine Hamel, Elise Launay, Romain Lamberet, Cédric Arvieux, Pierre Tattevin

\section{To cite this version:}

Aurore Lamberet, Philippe Violas, Sylvie Buffet-Bataillon, Antoine Hamel, Elise Launay, et al.. Postoperative Spinal Implant Infections in Children. Pediatric Infectious Disease Journal, 2018, 37 (6), pp.511-513. 10.1097/INF.0000000000001812 . hal-01812468

\section{HAL Id: hal-01812468 \\ https://hal-univ-rennes1.archives-ouvertes.fr/hal-01812468}

Submitted on 11 Jun 2018

HAL is a multi-disciplinary open access archive for the deposit and dissemination of scientific research documents, whether they are published or not. The documents may come from teaching and research institutions in France or abroad, or from public or private research centers.
L'archive ouverte pluridisciplinaire HAL, est destinée au dépôt et à la diffusion de documents scientifiques de niveau recherche, publiés ou non, émanant des établissements d'enseignement et de recherche français ou étrangers, des laboratoires publics ou privés. 


\section{The Pediatric Infectious Disease Journal Publish Ahead of Print}

\section{DOI: 10.1097/INF.0000000000001812}

Postoperative Spinal Implant Infections in Children: Risk Factors, Characteristics, and

\section{Outcome}

Aurore Lamberet, MD, ${ }^{*}, \uparrow$ Philippe Violas, MD, PhD, + Sylvie Buffet-Bataillon, MD,\$

Antoine Hamel, MD, PhD,\# Elise Launay, MD,§, Romain Lamberet, MD, \$, Cédric Arvieux, $\mathrm{MD}, \dagger$ and Pierre Tattevin, $\mathrm{MD}, \mathrm{PhD} \dagger$

From the : "Department of Pediatrics, Rennes University Hospital, France; $\uparrow$ Infectious

Diseases and Intensive Care Unit, Rennes University Hospital, France; $₫$ Department of Pediatric Surgery, Rennes University Hospital, France; Rennes University Hospital, France;

\$Department of Infection Control and Prevention, Rennes University Hospital, France, \#Department of Pediatric Surgery, Nantes University Hospital, France, §Department of Pediatrics, Nantes University Hospital, France, \$ Infectious diseases, Nantes University Hospital

Correspondence and reprints: Prof. Pierre Tattevin, Infectious Diseases and Intensive Care Unit, Pontchaillou University Hospital, 2, rue Le Guilloux, 35033 Rennes Cedex, France. Tel +33 299289564.Fax +33 299282452 E-mail address: pierre.tattevin@chu-rennes.fr

No funding was received for this study

Abbreviated title : Postoperative Spinal Implant Infections in children

Running head title : Postoperative Spinal Implant Infections

Conflict of interest : none 
Background: Postoperative infection is a major complication of spinal surgery with implants. We aimed to identify risk factors for, and characteristics of, postoperative spinal infections in children.

Methods: We performed a retrospective observational study of all children who underwent posterior spinal fusion with instrumentation in two referral hospitals in 2008-2013. Spinal infections were defined as local and/or general signs of infection that required surgical treatment in the early postoperative phase (i.e. within 30 days). Data were collected on a standardized questionnaire from medical charts.

Results: Of the 450 children who underwent spinal surgery, 26 (5.8\%) were diagnosed with early postoperative spinal implant infection, with a median age of 14 years [interquartile range, 13-17], and a median delay of 13 days post-surgery [IQR, 7-18]. Postoperative infection was more common in children with neurologic scoliosis as compared with idiopathic scoliosis $(12.2 \%(15 / 123)$ vs $2.4 \%(5 / 211) ; \mathrm{P}<0.01)$. Neurologic scoliosis was an independent predictor of spinal implant infections (HR 3.87 [1.72-8.69]; $\mathrm{P}<0.001)$. Main pathogens were Staphylococcus aureus $(\mathrm{n}=14)$, and Enterobacteriaceae $(\mathrm{n}=8)$. All children underwent early surgery (wound exploration, debridement, lavage), and antibiotics for a median duration of 19 weeks [IQR, 12-26]. Two children (7.7\%) required a second surgery. Spinal implants could be retained in all, and no relapse occurred with a follow-up of $\geq 24$ months after antibiotic discontinuation.

Conclusion: Postoperative spinal implant infection is not rare in pediatric patients, especially with neurologic scoliosis. Most children may be cured with implant retention if managed with early surgery followed by a 3-months course of appropriate antibacterial agents.

Keywords : spinal implant; post-operative infection; Staphylococcus aureus;

Enterobacteriaceae 


\section{INTRODUCTION}

Spinal deformity in children may require complex surgery, including posterior spinal fusion with instrumentation. Postoperative infection is a major complication of spinal implants, reported in $0.5-3 \%$ of children operated for idiopathic scoliosis, and 3.8-13.3\% of children operated for neurologic scoliosis [1-5]. Although device removal would be desirable to reduce bacterial burden and remove the biofilm, this option is not realistic in early postoperative infections, as it threatens spinal stability. Hence, management relies on early surgery with wound exploration, thorough debridement and lavage, followed by prolonged antibacterial treatment $[3,6,7]$. The optimal duration of antibiotics post-debridement is not defined, and some experts advocate for long-term antimicrobial therapy [8], although a landmark study in adults found that a 3-month course of antibiotics post-debridement cures most spinal implant infections [9]. We aimed to identify risk factors for early postoperative infections after spinal implantation in children, and to characterize these infections, their management, and outcomes.

\section{MATERIALS AND METHODS}

\section{Study design}

We performed a retrospective, observational study of all children $<21$-year old who underwent posterior spinal fusion with instrumentation during years 2008-2013 in Rennes and Nantes university hospitals, the referral centers for spinal surgery in children for Western France (population catchment area, 7 million inhabitants). Peri-operative antibiotic prophylaxis was administered in all children, 0-60 minutes before skin incision, with cefamandole from 2008 to 2011, or cefazolin in 2012-2013, $50 \mathrm{mg} / \mathrm{kg}$ ( $\max 2 \mathrm{~g}$ ), and was repeated once 4 hours later if the surgery was still ongoing. After surgery, children were routinely followed-up in their referral center during 24 months. Spinal infections were defined as local and/or general signs of infection that required surgical treatment in the early 
postoperative phase (i.e. within 30 days). No written protocol for spinal implant infections in children was available during the study period, but all cases were managed by a multidisciplinary team including pediatric surgeon(s), pediatrician(s), infectious diseases specialist(s), and microbiologist(s).

\section{Data collection}

Children who underwent spinal surgery were identified through review of pediatric surgery operation programs, the 'Q-planner'. Postoperative infections were identified through i) department of infection control computerized database, with prospective collection of all postoperative infections since 2007 (mandatory notification); ii) pediatric surgeons registry. Data were collected by one investigator $(\mathrm{AL})$ on a standardized questionnaire from medical charts, including: demographics, underlying spinal disease, surgery (duration, device implanted, antibiotic prophylaxis), delay between surgery and symptoms onset, between symptoms onset and debridement, microbiology, antibacterial treatment, and outcome. All infected patients were followed-up for $\geq 24$ months after antibiotic discontinuation.

\section{Statistics}

Continuous variables were expressed as median [interquartile range], and compared using Student t-test or Mann-Whitney U-test. Categorical variables were expressed as numbers (\%), and compared using $\mathrm{Chi}^{2}$ or Fisher exact tests. $\mathrm{P}<0.05$ was considered statistically significant. For multivariate analysis, all variables with $\mathrm{P}<0.1$ by univariate analysis were evaluated using a stepwise logistic regression model. Logistic regression analyses were performed using SPSS software, version 16.0.

\section{RESULTS}

From 2008 to 2013, 450 children underwent surgery for spinal deformity with implantation of spinal rods in Rennes $(n=258)$, or Nantes $(n=192)$. Of these, 26 (5.8\%; 95\% confidence interval, 3.8-8.4\%) developed postoperative spinal implant infections. All children with spinal 
implant infections had fever $\left(\geq 38.3^{\circ} \mathrm{C}\right)$, and local signs of infection (purulent wound discharge, inflammation, and/or wound dehiscence). Median plasma C-reactive protein concentration was $63 \mathrm{mg} / \mathrm{L}$ [IQR 40-194] and median white blood cells count was $10.5 \mathrm{G} / \mathrm{L}$ [IQR 8-17]. On univariate analysis, neuromuscular scoliosis and long duration of surgery were associated with spinal implant infection (Table 1). On multivariate analysis, neuromuscular scoliosis was the only predictor of spinal implant infections (HR 3.87 [1.728.69]; $\mathrm{P}<0.001)$.

All patients underwent posterior spinal fusion with implantation of spinal titanium rods, various implants (screws, hocks and ligaments), and bone grafts. Median time between initial surgery and symptoms of infection was 13 days [IQR, 7-18]. Median time between symptoms onset and debridement was 17 days [IQR, 9-23]. Surgical treatment of postoperative infections consisted of scar incision, wound exploration, debridement and high volume-lavage (3-6 L of sterile water with chlorhexidine 0.05\%). Spinal implants were retained in all patients. Multiple samples were immediately sent to the laboratory, following principles applied for prosthetic joint infections: i) ideally, 5 samples from different sites; ii) areas with macroscopic signs of infection to be prioritized; iii) routine cultures to be prolonged 7 days to identify slow-growing organisms, including coagulase-negative staphylococci, and Propionibacterium acnes. Immediately following peroperative sampling, high-doses intravenous anti-staphylococcal therapy was started in all children (vancomycin or cloxacillin, based on risk factors for meticillin-resistant S. aureus), associated with gentamicin or cefotaxime in, respectively, 13 and 12 children.

Microbiologic documentation was obtained in 25 children, including 8 (32\%) polymicrobial (Table 2). Main pathogens were Staphylococcus aureus $(\mathrm{n}=14$, all meticillin-susceptible $S$. aureus, MSSA), and Enterobacteriaceae (n=8, with no isolate resistant to third-generation cephalosporin or fluoroquinolone). Of note, all the patients who developed postoperative 
Enterobacteriaceae infections ( $\mathrm{n}=7$ ), had neurologic scoliosis. Only two children had positive blood cultures. Twenty-four children underwent oral switch after a median duration of 17 days [IQR, 8-39] with intravenous therapy. Oral therapy was a rifampicin-fluoroquinolone combination in 17 patients $(71 \%)$. Adverse events requiring treatment alterations were i) rifampicin-related nausea and vomiting $(n=3)$, that resolved after dose reduction; ii) ciprofloxacin-related increase in the incidence of seizures in a child with preexisting convulsive encephalopathy, that required ciprofloxacin discontinuation. Median duration of antibacterial treatment was 19 weeks [IQR, 12-26] overall, but differed between the 2 hospitals, with a median duration of 12 weeks in Rennes [IQR, 6-12], versus 26 weeks in Nantes [IQR, 26-26, $\mathrm{P}<0.05]$.

All children were cured, with a follow-up $\geq 24$ months after treatment discontinuation, despite spinal implants were retained in all. Two children with MSSA infections initially underwent partial surgery with limited incision and incomplete wound exploration: Both required one additional surgery with extensive wound exploration, debridement and lavage. Samples taken during the second surgery yielded MSSA again for one child and P. acnes for the other. Both were finally cured with an additional 12 weeks of appropriate antibacterial treatment.

\section{DISCUSSION}

The incidence of postoperative spinal implant infections was $5.8 \%$ overall in this cohort, in agreement with other studies [1-10]. The risk was higher in children with neuromuscular scoliosis, as previously reported [2, 4]. In addition, our study suggests for the first time that spinal implant infections in patients with neuromuscular scoliosis is more likely to be related to Enterobacteriaceae. Indeed, children with neuromuscular lesions, including paraplegia and anal incontinence, may be at increased risk of scar contamination with digestive microbiota, due to the proximity between the lower extremity of the scar (i.e. lumbar spine) and the anus. This pathway should be considered for the prevention of postoperative infections in children 
operated for neuromuscular spinal deformity, with reinforced infection control policy, closer monitoring of surgical scars, and early change of wound dressings in case of potential contamination.

Pathogens responsible for postoperative spinal implant infections in this study are in agreement with previous reports [10], with a predominance of Staphylococcus sp., Enterobacteriaceae, $P$. acnes, and $P$. aeruginosa. Empirical treatment for postoperative spinal infections in our institutions includes piperacillin/tazobactam and gentamicin, which ensures adequate coverage, pending adjustment based on microbiologic documentation and drug susceptibility testing. Optimal duration of antibacterial treatment for spinal implant infections remains unknown, due to the absence of comparative study in the field, and the lack of validated surrogate marker for cure that could be used to guide treatment discontinuation. Hence, most experts recommend prolonged antibacterial treatment, at least 3-6 months, although shorter treatment duration may be as effective. In adults, Dubée et al. convincingly demonstrated that a 3 month-course of antibacterial treatment is sufficient for most patients with early postoperative spinal implant infections [9]. In children, Ying Li et al. recommend parenteral antibiotics for a minimum of 4-6 weeks after debridement and lavage with implant retention, followed by oral antibiotics for 2-6 months [8]. The French Society of Infectious Diseases (SPILF) recommends 2 weeks of intravenous therapy for osteoarticular infections involving foreign devices, relayed by an oral combination during 6-12 weeks [7]. In our study, antibacterial treatment was not protocolized, but most children received either 6,12 or 24 weeks of antibiotics following debridement and lavage with retention of spinal implants, with a $100 \%$ success rate. Of note, more than two thirds of children received a combination of rifampicin and fluoroquinolone, the preferred regimen for oral step-down in foreign devicerelated infections when the bacteria involved are susceptible, for the following reasons: i) fluoroquinolones, and rifampicin are among the rare antibiotics with bactericidal activity on 
biofilm; ii) both penetrate well in bone tissues; iii) digestive absorption is excellent, so that oral administration is similar to intravenous in terms of plasma concentration. The two childen who required one additional surgical treatment for infection were those who underwent only partial surgery initially. These findings suggest that antibacterial treatment can be safely discontinued 3 months after surgical treatment of spinal implant infections, provided wound exploration, debridement and lavage, were rigorously performed. This is in line with current guidelines for the management of prosthetic joint infections in adults, with the 'Debridement, Antibiotics, and Implant Retention' (DAIR) approach, with cure rates $>90 \%$ provided surgical intervention was performed early (i.e. $<3$ weeks) after infection onset. Although this recommendation is a significant step forward as compared to current recommendations of 4-6 weeks intravenous, followed by 2-6 months oral antibiotics in children [8], this may still be quite conservative, as no failure was reported among the 4 children who received only 6 weeks postoperatively in our series.

This observational study has limitations. Firstly, data were collected retrospectively from medical charts, hence important information may be lost. Secondly, sample size was limited (although among the largest reported to date). Thirdly, management was not protocolized during the study period, with significant heterogeneity between the two sites. However, this study adds significant information on risk factors for, and characteristics of this major postoperative infection, and may contribute to reduce antibacterial treatment duration, given the $100 \%$ cure rates observed after adequate debridement and lavage with implant retention, followed by $6-12$ weeks of antibiotics. 


\section{REFERENCES}

1. Smith JS, Shaffrey CI, Sansur CA, Berven SH, Fu K-MG, Broadstone PA, et al. Rates of infection after spine surgery based on 108,419 procedures: a report from the Scoliosis Research Society Morbidity and Mortality Committee. Spine 2011;36(7):556-63.

2. Cahill PJ, Warnick DE, Lee MJ, Gaughan J, Vogel LE, Hammerberg KW, et al. Infection after spinal fusion for pediatric spinal deformity: thirty years of experience at a single institution. Spine 2010;35(12):1211-7.

3. Rihn JA, Lee JY, Ward WT. Infection after the surgical treatment of adolescent idiopathic scoliosis: evaluation of the diagnosis, treatment, and impact on clinical outcomes. Spine 2008;33(3):289-94.

4. Master DL, Connie P-K, Son-Hing J, Armstrong DG, Thompson GH. Wound infections after surgery for neuromuscular scoliosis: risk factors and treatment outcomes. Spine 2011;36(3):E179-85.

5. Stuart Mackenzie W.G., Matsumoto H., Williams B.A., Corona J, Lee C, et al. Surgical Site Infection Following Spinal Instrumentation for Scoliosis A Multicenter Analysis of Rates, Risk Factors, and Pathogens. J Bone Joint Surg Am 2013; 95(9):800-6.

6. Kowalski TJ, Berbari EF, Huddleston PM, Steckelberg JM, Mandrekar JN, Osmon DR. The Management and Outcome of Spinal Implant Infections: Contemporary Retrospective Cohort Study. Clin Infect Dis 2007;44(7):913-20.

7. Société de Pathologie Infectieuse de Langue Française (SPILF), Collège des Universitaires de Maladies Infectieuses et Tropicales (CMIT), Groupe de Pathologie Infectieuse Pédiatrique (GPIP), Société Française d'Anesthésie et de Réanimation (SFAR), Société Française de Chirurgie Orthopédique et Traumatologique 
(SOFCOT), Société Française d'Hygiène Hospitalière (SFHH), et al. [Clinical practice recommendations. Osteoarticular infections on materials (prosthesis, implant, osteosynthesis]. Med Mal Infect 2009;39(11):815-63.

8. Li Y, Glotzbecker M, Hedequist D. Surgical site infection after pediatric spinal deformity surgery. Curr Rev Musculoskelet Med 2012;5(2):111-9.

9. Dubée V, Lenoir T, Leflon-Guibout V, Briere-Bellier C, Guigui P, Fantin B. Threemonth antibiotic therapy for early-onset postoperative spinal implant infections. Clin Infect Dis 2012;55(11):1481-7.

10. Maesani M, Doit C, Lorrot M, Vitoux C, Hilly J, Michelet D, et al. Surgical Site Infections in Pediatric Spine Surgery: Comparative Microbiology of Patients with Idiopathic and Non idiopathic Etiologies of Spine Deformity. Pediatr Infect Dis J 2016;35(1):66-70. 
Table 1. Risk factors for spinal implant infections: univariate analysis

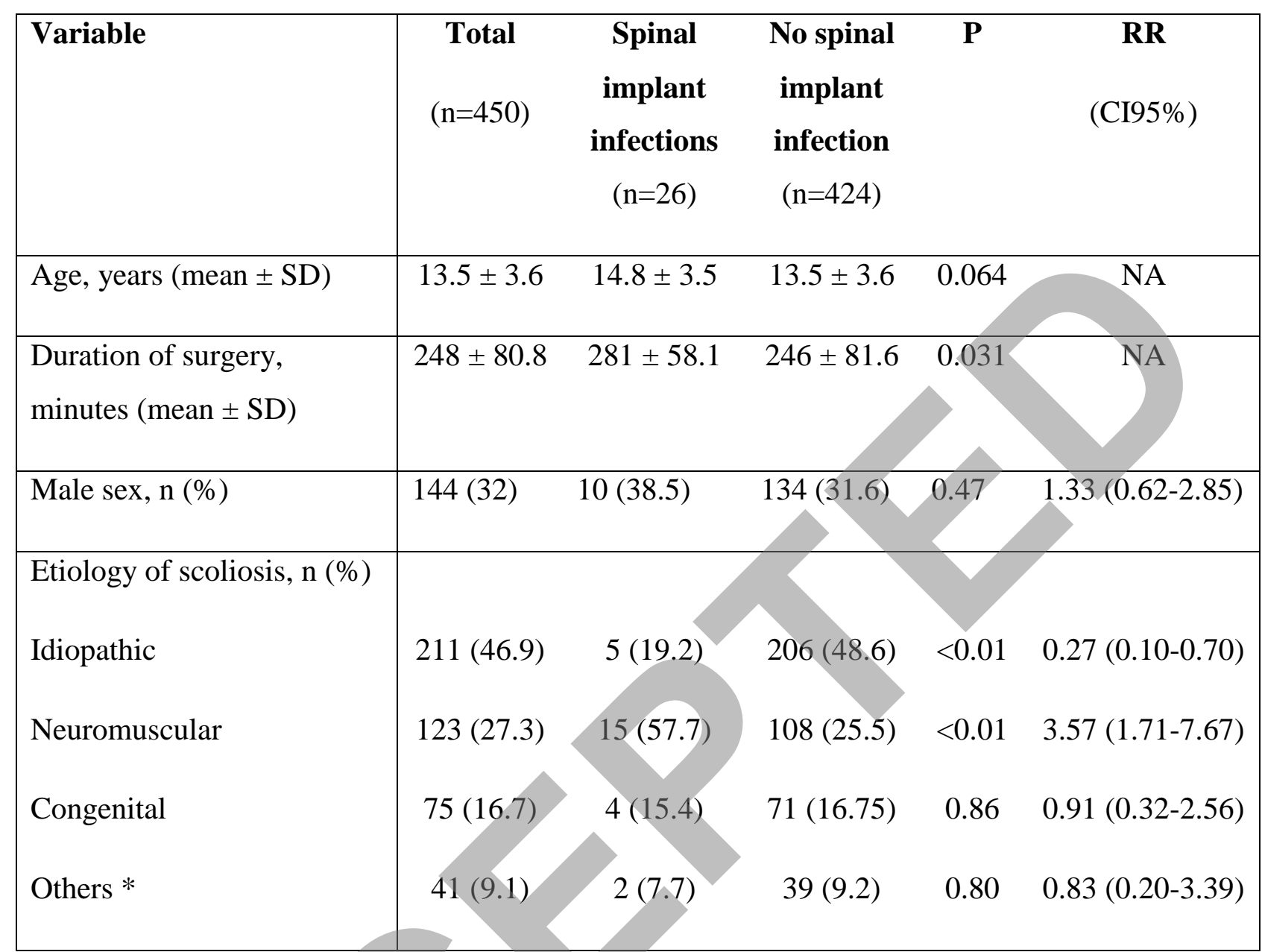

SD, standard deviation; NA, Non applicable

* Spondylolisthesis, trauma, cancer, benign tumor, miscellaneous genetic diseases 
Table 2. Microbiology of spinal implant infections $(n=26)$

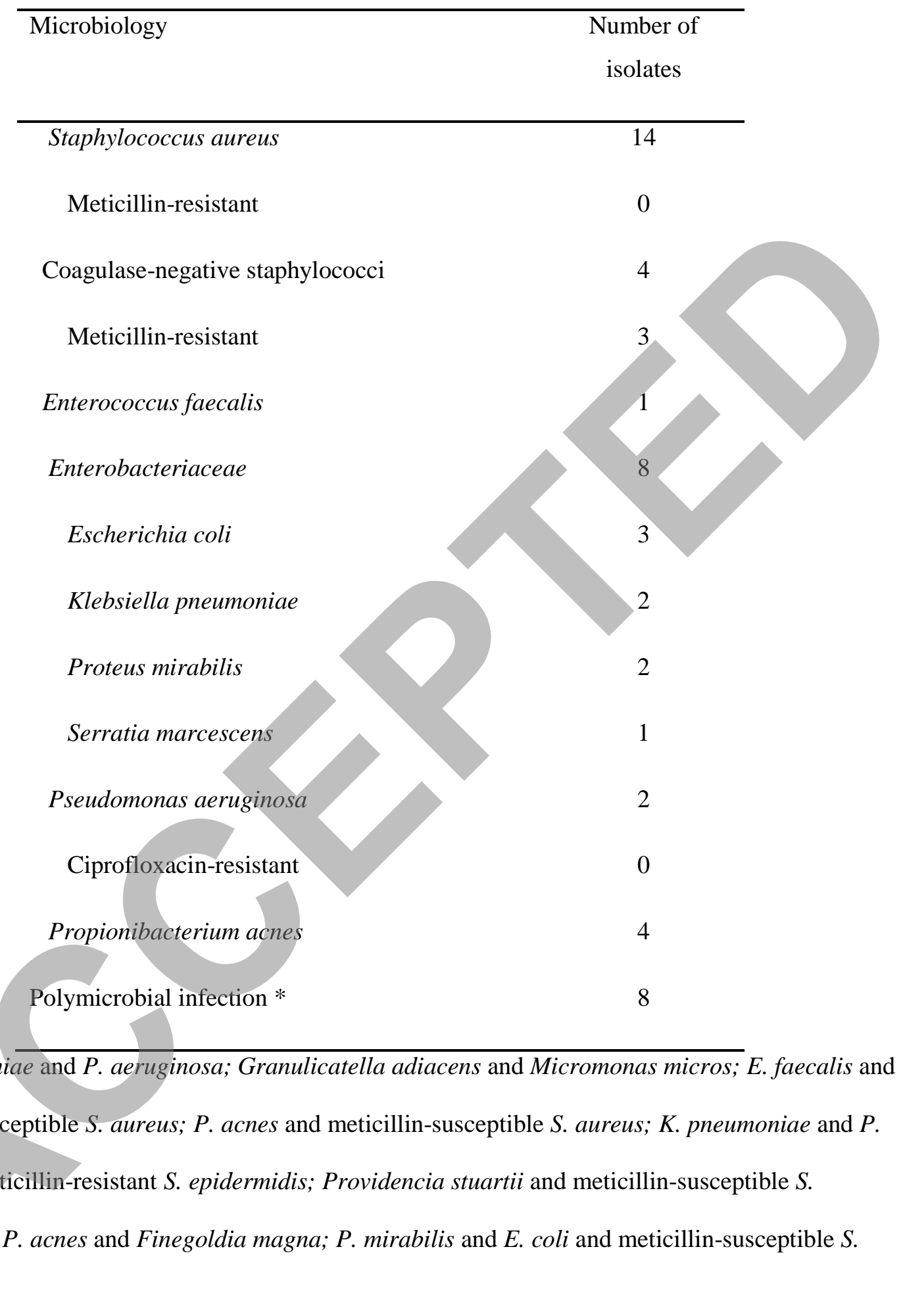

aureus; 